\title{
Neuropathic pain in a sample of Egyptian patients with rheumatoid arthritis
}

\author{
Abdullah Radwan ${ }^{1 *}$ and Ahmed Borai ${ }^{2}$
}

\begin{abstract}
Background: Rheumatoid arthritis (RA) is an autoimmune disease characterized by polyarthritis that may cause irreversible joint disability. Pain is the most important symptom in RA patients that requires more attention and careful evaluation. Despite the improvement in medications used to control inflammation in RA patients, a relevant number of them still experience neuropathic pain even with disease remission. This study was conducted to estimate the frequency of neuropathic pain (NP) in RA patients and to assess its relationship with disease activity, functional status, and overweight.

Results: NP was detected in $12.5 \%$ (14 patients) of RA patients. Highly significant differences were found between RA patients with NP and those without NP as regards disease duration, visual analog scale (VAS) of pain, disease activity score 28 (DAS28-ESR), erythrocyte sedimentation rate (ESR), C-reactive protein (CRP), body mass index (BMI), health assessment questionnaire (HAQ) score, and Douleur Neuropathique in 4 (DN4) questionnaire for NP assessment $(p<0.001)$. The correlation between the DN4 questionnaire and the parameters of disease activity in RA patients with NP was not significant. By univariate analysis, the possible risk factors for NP in RA patients were disease duration, VAS, DAS28-ESR, HAQ, and BMl; however, by multivariate analysis, no possible risk factors for NP in RA patients were detected.

Conclusion: Although pain in patients with RA was classified as nociceptive in nature, a relevant proportion of patients might also have NP. NP in RA patients was related to functional disability, high disease activity, and overweight.
\end{abstract}

Keywords: Rheumatoid arthritis, Douleur Neuropathique in 4 (DN4) questionnaire, Neuropathic pain

\section{Background}

Rheumatoid arthritis (RA) is a systemic autoimmune disease characterized by persistent, progressive synovitis, and structural damage that can result in progressive disability and loss of function [1]. Despite the significant improvement in RA management, persistent pain still presents in a relevant number of RA patients. Careful pain evaluation in RA patients will result in more advanced control of pain and better disease outcome [2].

Pain in patients with RA was described as nociceptive pain (inflammatory) and neuropathic pain. The nociceptors

\footnotetext{
* Correspondence: abdullahradwan@yahoo.com

1 Department of Rheumatology and Rehabilitation, Faculty of Medicine,

Sohag University, Nasser, Sohag, Egypt

Full list of author information is available at the end of the article
}

stimulated by chronic inflammation will result in nociceptive pain [3]. The International Association for the Study of Pain (IASP) defined the neuropathic pain (NP) as "pain caused by a primary lesion or dysfunction in the nervous system" [4]. Both hyperalgesia and allodynia are pathognomonic of NP [5].

$\mathrm{NP}$ and non-NP require different treatment modalities, so, for optimal treatment of NP, it should be properly evaluated and correctly diagnosed [6]. Patients describe NP as burning, tingling, pins and needles, electric shock feeling, and sensitivity to heat, cold, touch, or pressure [7]. Because of the overlap that can occur between NP and nociceptive pain in the pathophysiological mechanisms, several instruments have been developed for the assessment of pain [8]. 
According to IASP, careful history taking, proper clinical neurological examination, and sensory testing are recommended for NP diagnosis. To differentiate NP from non-NP, several screening tools were recommended by IASP [9].

One of the screening tools used for NP assessment is the Douleur Neuropathique in 4 (DN4) score which was developed by the French neuropathic pain group. The Pain DETECT questionnaire (PD-Q) is another screening tool developed for the assessment of NP [10].

The present study was carried out to estimate the frequency of NP in RA patients and to assess its relationship with disease activity, functional disability, and overweight.

\section{Methods}

This study was cross-sectional and performed on RA patients who attended the outpatient clinic of the Department of Rheumatology and Rehabilitation of our University Hospital in the period between December 2018 and May 2019. One hundred and twelve patients (9 males and 103 females) fulfilling the American College of Rheumatology/European league against rheumatism (ACR/EULAR) criteria for a diagnosis of RA [11] were randomly selected. RA patients with neurological diseases such as cerebrovascular disorders, multiple sclerosis, and peripheral neuropathy; those with fibromyalgia; and those with endocrine diseases such as diabetes mellitus and thyroid disorders were excluded from the study.

Patients were subjected to full history taking and thorough clinical examination. The erythrocyte sedimentation rate (ESR) $(\mathrm{mm} / \mathrm{h})$, C-reactive protein $(\mathrm{CRP})(\mathrm{mg} / \mathrm{l})$, rheumatoid factor $(\mathrm{RF})(\mathrm{U} / \mathrm{ml})$, and anti-cyclic citrullinated peptide (anti-CCP) $(\mathrm{U} / \mathrm{ml})$ were assessed. The disease activity score 28 ESR (DAS28-ESR) [12], the visual analog scale (VAS) of pain [13], and the body mass index (BMI) were measured. The functional status was evaluated by the health assessment questionnaire (HAQ) [14].

In the present study, a combination of methotrexate ( $15 \mathrm{mg} /$ week) and leflunomide $(20 \mathrm{mg} /$ day) were used for the treatment of RA patients. Due to the high cost of biologics, RA patients used this combination for good control of disease activity.

The NP was assessed by the DN4 score. This score is characterized by the easy translation to the Arabic language, simplicity in usage, and easy scoring. It included 10 items, seven of them included self-reported pain sensations (itching, tingling, numbness, pins and needles, painful cold, electric shock, and burning), while the remaining 3 items described the clinical findings (hypoesthesia to prick, hypoesthesia to touch, and brushing). Each item can be answered as "Yes" and takes 1 point or "No" and takes 0 points. The total score ranges from 0 to 10 , and the score of 4 or more $(\geq 4)$ is considered positive for NP. The sensitivity of this score is $83 \%$, and the specificity is $90 \%$ for the diagnosis of neuropathic pain. The diagnostic accuracy of the DN4 score is higher than other questionnaires used for the determination of neuropathic pain because of the presence of physical examination in this score [10].

Statistical analysis: Data was analyzed using IBM-SPSS statistics version 24 (May 2016, IBM Corporation, Chicago, USA) Qualitative data were expressed as numbers and percentages while quantitative data were expressed as means and SD. Pearson's chi-squared test was used to compare percentages in qualitative data. Student's $t$ test was used to compare the means between groups for quantitative data, and Mann Whitney's test was used instead of a $t$ test for non-parametric data. Pearson's correlation coefficient test was used to estimate correlations between different variables for parametric data, and Spearman's correlation test was used instead of non-parametric data. $P$-value was considered significant if $\leq 0.05$ and highly significant if $\leq 0.001$.

\section{Results}

A total of 112 patients with RA (9 males, 103 females; mean age $44.86 \pm 10.1$ years) were included in the study. The characteristics of RA patients with NP and those without NP are presented in Table 1. Highly significant differences were found between the two groups as regards disease duration, VAS, DAS28-ESR, ESR, CRP, BMI, HAQ, and DN4 $(p<0.001)$ (Table 1). The correlation between the DN4 questionnaire and parameters of disease activity in the group of RA patients with NP was not significant (Table 2). The univariate binary regression analysis showed that disease duration, VAS, total joint counts (TJCs), swollen joint counts (SJCs), DAS28ESR, ESR, CRP, BMI, and HAQ are possible risk factors for NP in RA patients (Table 3); however, no possible risk factors for NP in RA patients were detected by the multivariate analysis (Table 4).

\section{Discussion}

RA is a common autoimmune arthritis characterized by synovial changes, cartilage and bone destruction, joint swelling, and pain with associated systemic inflammation. The prognosis and control of RA have greatly improved especially when biologic disease-modifying anti-rheumatic drugs (DMARDs) were introduced for its management. However, some RA patients still suffer from severe pain [15].

Pain is categorized into nociceptive pain, NP, and mixed pain. RA, osteoarthritis, and trauma are categorized as nociceptive pain. Diabetic neuropathy, sciatic pain, and post-herpetic neuralgia are categorized as NP. Post-operative pain, the pain of lumbar disc hernia, and pain of spinal canal stenosis are categorized as mixed pain [16]. The concept of mixed pain may also be applied to RA, because different pain mechanisms operate in this type of pain. In RA patients, because of the 
Table 1 Comparison between RA patients with neuropathic pain and those without neuropathic pain

\begin{tabular}{|c|c|c|c|}
\hline Characteristics & $\begin{array}{l}\text { RA patients with } \\
\text { neuropathic pain } \\
(n=14)\end{array}$ & $\begin{array}{l}\text { RA patients without } \\
\text { neuropathic pain }(n=98)\end{array}$ & $P$ value \\
\hline Sex & & & 0.687 \\
\hline Male & $1(7.1 \%)$ & $8(8.2 \%)$ & \\
\hline Female & $13(92.9 \%)$ & $90(91.8 \%)$ & \\
\hline Age & $49 \pm 7.75$ & $44.27 \pm 10.29$ & 0.101 \\
\hline Education level & & & 0.898 \\
\hline No formal education & $9(64.3 \%)$ & $65(66.3 \%)$ & \\
\hline Primary education & $3(21.4 \%)$ & $14(14.3 \%)$ & \\
\hline Secondary education & $1(7.1 \%)$ & $10(10.2 \%)$ & \\
\hline Tertiary education & $1(7.1 \%)$ & $9(9.2 \%)$ & \\
\hline Disease duration (years) & $11.21 \pm 1.67$ & $4.66 \pm 1.47$ & 0.001 \\
\hline \multicolumn{4}{|l|}{$\mathrm{RF}(\mathrm{IU} / \mathrm{mL})$} \\
\hline Positive & $11(78.6 \%)$ & $70(71.4 \%)$ & 0.754 \\
\hline Negative & $3(21.4 \%)$ & $28(28.6 \%)$ & \\
\hline \multicolumn{4}{|l|}{ Anti-CCP (u/ml) } \\
\hline Positive & $7(50 \%)$ & $58(59.2 \%)$ & 0.515 \\
\hline Negative & $7(50 \%)$ & $40(40.8 \%)$ & \\
\hline VAS $(0-100 \mathrm{~mm})$ & $7.36 \pm 1.34$ & $1.91 \pm 1.08$ & $<0.001$ \\
\hline DAS-28 score & $5.27 \pm 0.82$ & $2.33 \pm 0.71$ & $<0.001$ \\
\hline $\mathrm{HAQ}$ & $1.19 \pm 0.41$ & $0.26 \pm 0.27$ & $<0.001$ \\
\hline BMI $\left(\mathrm{kg} / \mathrm{m}^{2}\right)$ & $24.07 \pm 1.98$ & $20.46 \pm 1.56$ & $<0.001$ \\
\hline $\operatorname{ESR}(\mathrm{mm} / \mathrm{h})$ & $54.14 \pm 19.73$ & $20.86 \pm 6.41$ & $<0.001$ \\
\hline CRP (mg/L) & $27.43 \pm 11.93$ & $4.13 \pm 3.89$ & $<0.001$ \\
\hline DN4 & $8.00 \pm 0.96$ & $1.88 \pm 0.82$ & $<0.001$ \\
\hline
\end{tabular}

Data was expressed as means \pm SD for quantitative data, and numbers and percentages for qualitative data. $P$ values were obtained using Pearson's chi-squared test for the comparison of percentages of qualitative variables between the two groups, and Fisher's exact test was used in cases of non-parametric data. On the other hand, $p$ values were obtained using independent $t$ test comparing the means of quantitative variables between the two groups, and Mann Whitney test was used instead of $t$ test to compare the median rather than the means in cases of non-parametric data

RF Rheumatoid factor, Anti-CCP Anti-cyclic citrullinated peptide, VAS Visual analog scale of pain, DAS-28 Disease activity for 28 joint indices score, HAQ Health assessment questionnaire, BMI Body mass index, ESR Erythrocyte sedimentation rate, CRP C-reactive protein, DN4 Douleur Neuropathique in 4 questionnaire

inadequate response of NP to the traditional antiinflammatory medications, and the association between NP and poor quality of life, it is important to address the presence of NP symptoms in RA [17].

In our study, based on the DN4 scores, NP was detected in $12.5 \%$ (14 patients) of RA patients. According to DN4 scores, Perrot et al. [18] detected NP in $36 \%$ of patients with RA while Cengiz et al. [19] detected NP in $45.3 \%$ of RA patients. This may be explained by the racial differences and the different sample sizes in the studied populations. By using the PD-Q, NP was detected in 33\% [20], in 17\% [16], and in 11\% [17] of RA patients. These results showed that, despite advancement in RA management, pain suppression in some patients remains inadequate, even with good control of inflammation. Therefore, inflammation is not the only parameter that predisposes to pain in RA; other parameters like NP can also have a role. Therefore, considering the NP component is essential in the optimal care of RA patients [19]. The first-line drugs for the management of NP were tricyclic antidepressant, pregabalin, and duloxetine, while the second line drug was tramadol. However, pregabalin is the only drug approved for treating NP in Japan [17]. Because the main adverse effects of pregabalin are weight gain and edema, attention should be paid to RA patients with NP when treating them with pregabalin.

In the present study, significantly higher levels of disease duration, VAS, DAS28-ESR, ESR, and CRP were reported in RA patients with NP than those without NP ( $p$ $<0.001)$. The univariate analysis detected these parameters as possible risk factors for neuropathic pain. However, no possible risk factors for NP were detected by the multivariate analysis. These results were consistent with those of Ito et al. [17] who found significantly higher levels of disease activity parameters in RA 
Table 2 Comparison between Douleur Neuropathique in 4 (DN4) questionnaire and other variables among RA patients with neuropathic pain $(n=14)$

\begin{tabular}{|c|c|c|c|}
\hline Characteristics & DN4 (mean \pm SD) & Correlation coefficient & $P$ value \\
\hline Sex & & & 0.298 \\
\hline Male & 7 & & \\
\hline Female & $8.08 \pm 0.95$ & & \\
\hline Age (years) & & 0.021 & 0.944 \\
\hline Disease duration (years) & & 0.239 & 0.410 \\
\hline \multicolumn{4}{|l|}{ RF (IU/mL) } \\
\hline Positive & $8.09 \pm 0.83$ & & 0.520 \\
\hline Negative & $7.67 \pm 1.53$ & & \\
\hline VAS (0-100 mm) & & 0.034 & 0.908 \\
\hline DAS-28 score & & -0.269 & 0.353 \\
\hline HAQ & & 0.087 & 0.769 \\
\hline BMI $\left(\mathrm{kg} / \mathrm{m}^{2}\right)$ & & 0.405 & 0.151 \\
\hline $\mathrm{ESR}(\mathrm{mm} / \mathrm{h})$ & & -0.312 & 0.277 \\
\hline CRP (mg/L) & & 0.483 & 0.080 \\
\hline
\end{tabular}

Data was expressed as means \pm SD of DN4 level between males and females, or between RF positive and negative patients, and for these, $p$ values were obtained using independent $t$ test. The correlation between DN4 and other quantitative variables was calculated using Pearson's correlation test for parametric variables and Spearman's correlation test for non-parametric variables

RF Rheumatoid factor, Anti-CCP Anti-cyclic citrullinated peptide, VAS Visual analog scale of pain, DAS28 Disease activity for 28 joint indices score, HAQ Health assessment questionnaire, $B M I$ Body mass index, ESR Erythrocyte sedimentation rate, CRP C-reactive protein

patients with NP than those without NP. The longer disease duration will give a chance to the neuropathic pain to become apparent. On the contrary, our results were inconsistent with those of Koop et al. [16]. According to these findings, more effective treatment strategies should be applied to RA patients especially those with NP.

In our study, patients with RA and NP showed significantly higher BMI values than those without NP. Similar results were found in other studies $[17,20]$. However, no

Table 3 Univariate binary logistic regression analysis of the possible risk factors for neuropathic pain among RA patients

\begin{tabular}{llll}
\hline Characteristics & $\boldsymbol{P}$ value & Odd's ratio & Cl of odd's \\
\hline Female sex & 0.896 & 1.156 & $0.133-10.007$ \\
Age & 0.104 & 1.050 & $0.990-1.113$ \\
Education & 0.859 & 0.947 & $0.527-1.701$ \\
Disease duration (years) & $<0.001$ & 3.305 & $1.876-5.824$ \\
RF & 0.578 & 1.467 & $0.380-5.656$ \\
Anti-CCP & 0.516 & 1.450 & $0.472-4.455$ \\
VAS & $<0.001$ & 4.586 & $2.176-9.664$ \\
DAS-28 score & $<0.001$ & 9.268 & $3.575-24.027$ \\
HAQ & $<0.001$ & 108.477 & $15.669-750.998$ \\
BMI $\left(\mathrm{kg} / \mathrm{m}^{2}\right)$ & $<0.001$ & 2.324 & $1.627-3.319$ \\
ESR & $<0.001$ & 1.192 & $1.106-1.284$ \\
CRP & $<0.001$ & 1.313 & $1.169-1.475$ \\
\hline
\end{tabular}

RF Rheumatoid factor, Anti-CCP Anti-cyclic citrullinated peptide, VAS Visual analog scale of pain, DAS28 Disease activity for 28 joint indices score, $H A Q$ Health assessment questionnaire, BMI Body mass index, ESR Erythrocyte sedimentation rate, $C R P C$-reactive protein association between NP and BMI was detected in the multivariate analysis which was inconsistent with that of Ito et al. [17] who found that BMI > 22 was associated with NP in the multivariate analysis. Pain and obesity have a complex relationship, and the association between NP and obesity is still unclear [17]. It has been suggested that obesity may be related to pain [21], and in contrast, chronic pain may lead to a sedentary lifestyle, resulting in obesity [17].

In the current study, patients with RA and NP reported higher HAQ scores compared to those without neuropathic pain which were in line with those of Koop et al. [16]. No association between HAQ scores and NP was detected in the multivariate analysis. This can be explained by the fact that HAQ scores are subjective measures and therefore may not necessarily detect the true functional disability [16].

In the present study, the correlation between the DN4 questionnaire and disease activity parameters in RA patients was not significant. Our results were consistent

Table 4 Multivariate binary logistic regression analysis of the possible risk factors for neuropathic pain among RA patients

\begin{tabular}{lllll}
\hline Characteristics & $\boldsymbol{P}$ value & Odd's ratio & Cl of odd's & Rank \\
\hline Disease duration (years) & 0.987 & 2.017 & $0.781-3.982$ & 2 \\
DAS-28 score & 0.992 & 1.868 & $0.443-2.119$ & 3 \\
HAQ & 0.990 & 3.200 & $0.711-5.829$ & 1 \\
$\mathrm{BMI}\left(\mathrm{kg} / \mathrm{m}^{2}\right)$ & 0.990 & 1.764 & $0.889-1.987$ & 4
\end{tabular}

DAS-28 Disease activity for 28 joint indices score, $H A Q$ Health assessment questionnaire, $B M I$ Body mass index 
with those of Koop et al. [16] but inconsistent with those of Perrot et al. [18]. This can be explained by the low sample size, racial difference, different disease duration and severity, and gender difference. Therefore, future larger studies are needed to clarify these results.

\section{Limitations}

First, NP diagnosis was only made by the DN4 questionnaire. Confirmation of the results can be done by using electrodiagnostic studies, including nerve conduction studies and electromyography. Second, for better interpretation of the present findings, another questionnaire like the PD-Q can be used in addition to the DN4 questionnaire in future studies. Third, psychological assessment for depression and anxiety that may be related to NP was not done. Fourth, it can be better to exclude RA patients treated with leflunomide because of leflunomideinduced neuropathy which may interfere with the interpretation of the present results. Finally, the low percentage of RA patients with NP and the predominance of females in the current study may prevent the generalization of the results. So, for an accurate understanding of NP in RA, future larger studies are needed to provide us with more professional approaches to pain management.

\section{Conclusion}

Although pain in RA patients is mainly classified as nociceptive, a relevant number of RA patients might also have NP. NP in RA patients is related to high disease activity, functional disability, and overweight.

\begin{abstract}
Abbreviations
RA: Rheumatoid arthritis RA; NP: Neuropathic pain; IASP: International association for the study of pain; DN4: Douleur neuropathique in 4; PDQ: Pain DETECT questionnaire; ACR/EULAR: American College of rheumatology/European league against rheumatismBMIBody mass index; DAS28-ESR: Disease activity score 28-ESR; VAS: Visual analog scale of pain; CRP: C-reactive protein; ESR: Erythrocyte sedimentation rate; HAQ: Health assessment questionnaire; Anti-CCP: Anti-cyclic citrullinated peptide; DMAR Ds: Disease-modifying anti-rheumatic drugs
\end{abstract}

\section{Acknowledgements}

The authors would like to thank all members of the Department of Rheumatology and Rehabilitation for their cooperation and support.

\section{Authors' contributions}

AR performed the examination and clinical assessment of rheumatoid arthritis patients, did the statistics of the study, and wrote the manuscript. AB examined and assessed the patients neurologically and shared in the writing of the manuscript. The authors read and approved the final manuscript.

\section{Funding}

The authors received no funding from any source.

\section{Availability of data and materials}

The data used to support the results of this research are within the study.

\section{Ethics approval and consent to participate}

The study has been approved by the Ethics Committee of Sohag University (approval no. 2018-234). Written informed consents were obtained from patients participating in the study.
Consent for publication

Not applicable.

\section{Competing interests}

The authors declare that they have no competing interests.

\section{Author details}

'Department of Rheumatology and Rehabilitation, Faculty of Medicine, Sohag University, Nasser, Sohag, Egypt. '2Department of Neuropsychiatry, Faculty of Medicine, Sohag University, Nasser, Sohag, Egypt.

Received: 14 September 2020 Accepted: 16 November 2020 Published online: 26 November 2020

\section{References}

1. Scott DL, Wolfe F, Huizinga TW (2010) Rheumatoid arthritis. Lancet 376(9746):1094-1108

2. Taylor P, Manger B, Alvaro-Gracia J, Johnstone R, Gomez-Reino J, Eberhardt E et al (2010) Patient perceptions concerning pain management in the treatment of rheumatoid arthritis. J Int Med Res 38(4):1213-1224

3. Siddall PJ, McClelland JM, Rutkowski SB, Cousins MJ (2003) A longitudinal study of the prevalence and characteristics of pain in the first 5 years following spinal cord injury. Pain 103(3):249-257

4. Jensen TS, Baron R, Haanpaa M, Kalso E, Loeser JD, Rice AS et al (2011) A new definition of neuropathic pain. Pain 152(10):2204-2205

5. Treede RD, Jensen TS, Campbell JN, Cruccu G, Dostrovsky JO, Griffin JW et al (2008) Neuropathic pain: redefinition and a grading system for clinical and research purposes. Neurology 70(18):1630-1635

6. Sommer C, Richter H, Rogausch JP, Frettloh J, Lungenhausen M, Maier C (2011) A modified score to identify and discriminate neuropathic pain: a study on the German version of the Neuropathic Pain Symptom Inventory (NPSI). BMC Neurol 11:104

7. Bennett Ml, Attal N, Backonja MM, Baron R, Bouhassira D, Freynhagen R et al (2007) Using screening tools to identify neuropathic pain. Pain 127(3):199-203

8. Breivik H, Borchgrevink PC, Allen SM, Rosseland LA, Romundstad L, Hals EK et al (2008) Assessment of pain. Br J Anaesth 101(1):17-24

9. Cruccu G, Truini A (2009) Tools for assessing neuropathic pain. PLoS Med 6(4):e1000045

10. Bouhassira D, Attal N, Alchaar H, Boureau F, Brochet B, Bruxelle J et al (2005) Comparison of pain syndromes associated with nervous or somatic lesions and development of a new neuropathic pain diagnostic questionnaire (DN4). Pain 114(1-2):29-36

11. Aletaha D, Neogi T, Silman AJ, Funovits J, Felson DT, Bingham CO 3rd et al (2010) 2010 Rheumatoid arthritis classification criteria: an American College of Rheumatology/European League Against Rheumatism collaborative initiative. Arthritis Rheum 62(9):2569-2581

12. Prevoo ML, van't Hof MA, Kuper HH, van Leeuwen MA, van de Putte $L B$, van Riel PL (1995) Modified disease activity scores that include twenty-eightjoint counts. Development and validation in a prospective longitudinal study of patients with rheumatoid arthritis. Arthritis Rheum 38(1):44-48

13. Mallya RK, Mace BE (1981) The assessment of disease activity in rheumatoid arthritis using a multivariate analysis. Rheumatol Rehabil. 20(1):14-17

14. Wolfe F, Kleinheksel SM, Cathey MA, Hawley DJ, Spitz PW, Fries JF (1988) The clinical value of the Stanford Health Assessment Questionnaire Functional Disability Index in patients with rheumatoid arthritis. J Rheumatol 15(10):1480-1488

15. Yamanaka H, Seto Y, Tanaka E, Furuya T, Nakajima A, Ikari K et al (2013) Management of rheumatoid arthritis: the 2012 perspective. Modern Rheumatol 23(1):1-7

16. Koop SM, ten Klooster PM, Vonkeman HE, Steunebrink LM, van de Laar MA (2015) Neuropathic-like pain features and cross-sectional associations in rheumatoid arthritis. Arthritis Res Ther 17:237

17. Ito S, Kobayashi D, Murasawa A, Narita I, Nakazono K (2018) An analysis of the neuropathic pain components in rheumatoid arthritis patients. Intern Med 57(4):479-485

18. Perrot S, Dieude P, Perocheau D, Allanore Y (2013) Comparison of pain, pain burden, coping strategies, and attitudes between patients with systemic sclerosis and patients with rheumatoid arthritis: a cross-sectional study. Pain Med 14(11):1776-1785

19. Cengiz G, Erol K, Gok K, Ozgocmen S (2018) Comparison of pain characteristics in patients with rheumatoid arthritis and systemic sclerosis 
with particular reference to the neuropathic pain component: crosssectional study. Med Princ Pract 27(6):537-542

20. Ahmed S, Magan T, Vargas M, Harrison A, Sofat N (2014) Use of the painDETECT tool in rheumatoid arthritis suggests neuropathic and sensitization components in pain reporting. J Pain Res 7:579-588 21. McVinnie DS (2013) Obesity and pain. Br J Pain 7(4):163-170

\section{Publisher's Note}

Springer Nature remains neutral with regard to jurisdictional claims in published maps and institutional affiliations.

\section{Submit your manuscript to a SpringerOpen ${ }^{\mathcal{O}}$} journal and benefit from:

- Convenient online submission

- Rigorous peer review

- Open access: articles freely available online

High visibility within the field

- Retaining the copyright to your article

Submit your next manuscript at $\boldsymbol{\wedge}$ springeropen.com 